\title{
Keys to the Successful Indexing of the Archives of Plastic Surgery in Science Citation Index Expanded
}

\author{
Nayoung Kim ${ }^{1,2}$, Gi Hyun Kim ${ }^{1}$ \\ 'Department of Internal Medicine, Seoul National University Bundang Hospital, Seongnam; ${ }^{2}$ Department of \\ Internal Medicine and Liver Research Institute, Seoul National University College of Medicine, Seoul, Korea
}

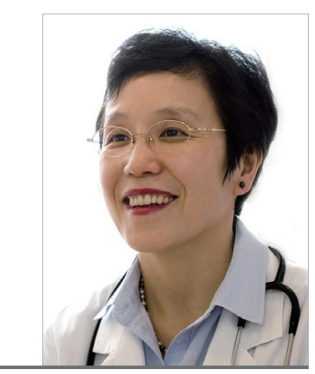

Recently, we were invited to attend the workshop for members of the Editorial Board of the Archives of Plastic Surgery (APS) to share our experience of the Science Citation Index Expanded (SCIE) indexing of the Journal of Neurogastroenterology and Motility (impact factor [IF] of 2013, 2.698). The Editor-in-Chief wanted us to review two issues of APS and to comment on them. Through this experience, we assessed the strengths and weaknesses of APS and how to compensate for the weaknesses.

APS, the official journal of the Korean Society of Plastic and Reconstructive Surgeons, is published six times a year, every other month. This journal is a peer reviewed and open access journal, the full text of each article is available online, and the articles are required to be written in English. The self-analyzed IF has been estimated at $0.6-0.9$ points $[1,2]$. To our understanding, APS has major strengths. Among the parts of a paper, the abstract part looks very good; it is framed by a colored box, which allows readers to identify it with ease. Likewise, the figures are arranged with appropriate size and with high resolution, drawing readers into the articles. Thanks to the editor's effort, the majority of articles in the past two years of publication were submitted by non-Korean authors. In 2012, only 10 papers were published from 7 countries excluding Korea, while 49 papers were published from 23 countries in 2013 [3]. In addition, open access online has increased the accessibility of this journal.

However, some parts of the journal require correction in order to continue to build APS to a higher level academic journal. First of all, APS includes case reports and images. Although the impact factor is not an absolute standard for assessing the quality of a journal, many academic journals use the impact factor as an indicator for evaluating the impact of articles. Since case reports and images are less likely to be cited in other journals than original articles and reviews, they play a role in undermining the impact factor of the articles overall. Therefore, APS needs to place greater emphasis on reviews and original articles than case reports and images. Secondly, the fact that the records on research approval have been omitted from many articles of APS is also a matter of general concern. Many academic journals recently have begun to emphasize strict research ethics and require Institutional Review Board (IRB) approval not only for prospective but also retrospective research. For example, all of the original articles published in Plastic and Reconstructive Surgery Journal in August 2014 specify research approval, whereas 9 of 16 original articles recently published in APS in July 2014 have neither research approval nor IRB approval. Thirdly, the fact that the regulations for submission have not been complied with well and the fact that the format has not been standardized is also problematic. Although the submission rules for the figure title of APS say to use a short tile with 5-7 words, 3 out of 16 articles published in July 2014 did not comply with the rules.

In addition, 4 out of 16 articles did not exactly indicate the roles of authors, and 4 articles reported $\mathrm{P}$-values in ways that were incompatible with the rules. Many articles have used various expressions, such as "X," "not significant," "NS," to indicate that there is no statistical significance, and the phone numbers of authors have several formats. The fact that the way to express the decimal places in tables varies in different articles also needs to 
be corrected.

In summary, to increase its IF, APS needs to increase the proportion of original articles relative to case reports, and to endeavor to publish review articles on recent problems or issues in order for the journal to move toward publishing articles with a stronger impact. In addition, APS needs to indicate IRB or research approval in the methods part of all articles and maintain uniformity among articles by locating the research approval or statistical methods in the same place. In addition, assigning someone other than the editors to uniformly define the format and content of the role of authors and phone numbers may take the journal one step further toward excellence.

APS is the only plastic surgery clinical journal in English published in Korea, and its influence is expanding throughout Asia and beyond. We expect that APS can develop into an academic journal that leads plastic surgery in Asia in the near future through the improvements mentioned above.

\section{REFERENCES}

1. Scopus. Lists of APS article quoted in SCI(E) (2012-2013) [Internet]. Oxford: Elsevier B.V.; c2014 [2014 Jul 1]. Available from: http://www.scopus.com.

2. Web of science [Internet]. Philadelphia: Thomson Reuters; c2014 [cited 2014 Jul 1]. Available from: http://wokinfo. $\mathrm{com} /$.

3. Kim JT. Where is Archives of Plastic Surgery now? And where is it heading? Arch Plast Surg 2014;41:309-11.

Correspondence: Nayoung Kim

Department of Internal Medicine, Seoul National University Bundang Hospital, Seoul National University College of Medicine, 82 Gumi-ro 173beon-gil, Bundang-gu, Seongnam 463-707, Korea

Tel: +82-31-787-7008, Fax: +82-31-787-4051, E-mail: nayoungkim49@empas.com

No potential conflict of interest relevant to this article was reported.

Received: 15 Jan $2015 \bullet$ Revised: 18 Jan 2015 • Accepted: 19 Jan 2015

pISSN: 2234-6163 • elSSN: 2234-6171

http://dx.doi.org/10.5999/aps.2015.42.2.109 • Arch Plast Surg 2015;42:109-110 